\title{
ASSESSMENT OF HEPATOPROTECTIVE ROLE OF PHENOLIC EXTRACT OF URTICA DIOICA AND SILVER NANOPARTICLES IN MALE RAT INDUCED BY CARBON TETRA-CHLORIDE
}

\author{
M. M. Kadhim ${ }^{1, *}$, A.N. Aldujaili ${ }^{2}$ and M.H. Homady ${ }^{3}$ \\ ${ }^{1}$ Technical Institute of Diwaniyah/AL-Furat AL-Awsat Technical University, Najaf, Iraq \\ ${ }^{2,3}$ Department of Biology, College of Science/University of Kufa, Najaf, Iraq \\ *E-mail: murtadham.alkhafaji@student.uokufa.edu.iq
}

\begin{abstract}
This study showed the protective role of the phenolic extract of Urtica dioica and silver nanoparticles (AgNPS) on the hepatotoxicity effect via carbon tetrachloride $\left(\mathrm{CCL}_{4}\right)$ within white male rats. Hundred and ten male albino rats weighing (200-250g) and aged (10-17week). Animals were housed in the animal house of faculty of Science/University of Kufa under control condition; light 12 and 12 dark hours and temperature $\left(24 \pm 2 \mathrm{C}^{\circ}\right)$. Animals divided into four groups as follows the control groups, carbon tetrachloride groups, phenolic extract groups, and silver nanoparticles, groups. Subdivided groups above depending on the concentration $(250$ and $500 \mathrm{mg} / \mathrm{kg}$ ) of phenolic extract, (10 and $5 \mathrm{mg} / \mathrm{kg}$ ) of silver nanoparticles for (two and three) month add to dosage after and before induced by carbon tetrachloride (five animals per group). The current study revealed the occurrence of a significant decrease $(\mathrm{P} \leq 0.05)$ in the level of regucalcin when the administered by phenolic extract and silver nanoparticles for (two and three months) compared with carbon tetrachloride group. Highly significant $(\mathrm{p} \leq 0.05)$ with the concentration of the $(500 \mathrm{mg} / \mathrm{kg})$ for phenolic extract and $(10 \mathrm{mg} / \mathrm{kg})$ for silver nanoparticles, and no significant observed between extract and silver nanoparticles for (two and three months) and before and after induced by the carbon tetrachloride.
\end{abstract}

Keywords: Carbon tetrachloride, Hepatotoxicity, Urtica dioica, Silver nano-particles, Regucalcin.

(c) RASĀYAN. All rights reserved

\section{INTRODUCTION}

Liver occupies the first degree in the most management the important of human body, so it is the largest organ of the achievement of important functions and is one of the main focus for construction and secretion and contribute to the metabolism and storage operations for the liver importance in most homeostasis processes and energy saving, as well as the production of bile ${ }^{1}$. The detoxification of the greatest pivotal functions of the body being responsible for the process of converting and removing harmful substances ${ }^{2}$. Carbon tetrachloride is extensively employed for initiation of liver injury. ${ }^{3}$ Carbon tetrachloride has been widely used as a model of toxicity-induced chronic liver injury, progressing to fibrosis and cirrhosis ${ }^{4,5}$. The belief causes of carbon tetrachloride are provoked hepatic destruction in lipid peroxidation and decline action of antioxidant enzymes and accumulation of free radicals. ${ }^{6,7}$

Urtica dioica $\mathrm{L}$. herbaceous plant that grows over a wide area of the world belongs to the family Urticaceae and includes more than sixty genera and about more than seven hundred species the commonly known as Stinging Nettle. ${ }^{8,9}$ The diskette leaves rich in fine hair, which irritates the skin on contact because they contain many materials including acetylcholine, histamine. ${ }^{10,11}$ Previous studies have shown phytochemical compounds as flavonoids, tannins, volatile compounds and sterols. ${ }^{9,12,13}$ Common uses of $U$. dioica in the treatment of arthritis and rheumatic add to the diuretic agent. ${ }^{14}$ Utilised $U$. dioica extract to the prevention of hepatic and renal diseases because of the functions which are performed by such activate antioxidants system and destroy free radicals in addition to protective in the hepatic ischemia-reperfusion injury in rats. ${ }^{15-18}$ 
Nano-science techniques are one of most advanced science in the production of small molecules and compounds which could alter the properties and qualities of certain materials when they are nanometer size, which makes it more useful than the larger particles. ${ }^{19,20}$ Nanoparticles are working to increase the solubility and effectiveness of medicines in addition to accelerating the reaction and the delivery to the specific target. ${ }^{19,21}$ Many studies have explained the effect of silver nanoparticles wound healing and antibacterial and effectiveness anticancer and atherosclerosis to the mechanics of silver nanoparticles on free radical scavenger. ${ }^{19,21-25}$

Initially discovered regucalcin as $\mathrm{Ca}^{+2}$-binding protein was in $1978 .{ }^{26}$ Regucalcin composed of peptide chain and molecular mass $(30 \mathrm{kDa})$, regucalcin associated with ageing, so-called senescence marker protein30 (SMP30). ${ }^{27}$ The regucalcin mouse resembles rat $94 \%$, while $89 \%$ of the human. Which indicates the presence of a primary structure of regucalcin common between humans and rodents ${ }^{28}$. Study on human tissues and found varying expressions occurring in the cardiac tissue and pancreas, as well as already expressions in the tissues of the hepatic and renal tissues. ${ }^{28,29}$ Regucalcin plays a pivotal role in cell regulation: maintaining of intracellular $\mathrm{Ca} 2+$ homeostasis. ${ }^{30}$ Regucalcin plays a pivotal role in cell regulation and maintaining of intracellular $\mathrm{Ca} 2+$ homeostasis. ${ }^{31}$ Serum regucalcin has been detected to raise with liver injury, and besides urinary regucalcin is raise with kidney illness, recommend a beneficial agent as a biomarker for investigation..$^{32,33}$

Therefore, the current studies must be subjected to find natural alternatives from plants which have side effects almost non-existent and in addition to the referencing and the use of folk herbal according to modern methods to extract useful such materials. Also, has to be considered to technology and modern science in the treatments where is the science and applications of nanotechnology leading in finding alternatives to treat diseases such as liver disease.

\section{General procedure}

Preparation of Carbon Tetrachloride

Carbon Tetrachloride $\left(\mathrm{CCl}_{4}\right)$ were gotten from [Merck Ltd., Coimbatore, Tamilnadu (India)]. CCL4 $\left[(1 \mathrm{ml} / \mathrm{kg}\right.$ body weight $)$ consolidated with olive oil [1:1]. ${ }^{34}$ The procedure of $\mathrm{CCL}_{4}$ doses administration to male animal rats was orally for two and three months.

\section{Preparation of silver nanoparticles}

The silver nanoparticles are manufactured by (Nd-YAG Laser and UV-vis spectrum) in laboratories of Nanotechnology Center/University of Kufa. Nanoparticles are administered orally at two doses (10 and 5 $\mathrm{mg} / \mathrm{kg}$ ) for two and three months before and after 2 hours of $\mathrm{CCL}_{4}$ administration.

\section{Preparation of phenolic extract}

Powder of U.Dioica leaves was obtained from botany gardens of Baghdad University. The phenolic extract was prepared by adding $200 \mathrm{~mL}$ of methanol alcohol to $20 \mathrm{~g}$ of powder, by using Sexholate for 24 hours, the extract was evaporated on a rotary evaporation under vacuum at a temperature of $60 \mathrm{C}^{\circ}$ until the solution reached to $10 \mathrm{~mL}$. Then, the solution was transferred to a separation funnel and add 2N HCL was added gradually to get $\mathrm{PH}=2$, then, washed with $10 \mathrm{~mL}$ of chloroform three times. The solution was separated into two layers, the lower layer was dried which is phenolic, weighted and stored in a refrigerator until using. ${ }^{35}$

\section{Detection Method}

\section{Determination of phenolic compounds}

The triple drops of $1 \%$ ferric chloride $\left(\mathrm{FeCl}_{3}\right)$ solution was combined with $2 \mathrm{~mL}$ of each extract. The presentation of thick lavender color with ferric ions designate the presence of Phenolic compounds. ${ }^{36}$

\section{Determination regucalcin protein}

The assessment of regucalcin rats Elisa kits provided by (elabscience - china) Sandwich immunoassay technique (enzyme-linked immunosorbent assay - automated microtiter plate), Elisa reader (Biokit ELX 800 reader, ELX50 washer/USA). 


\section{Analytical Discussion}

Results are represented as mean \pm standard error (SE) and performed using one-way ANOVA by GraphPad Prism ${ }^{\circledR}$ software (GraphPad Software, Inc., La Jolla, CA, USA) L.S.D was P $\leq 0.05$ in study groups and data were compared between groups using T-test. ${ }^{37}$

\section{Result of $\boldsymbol{U}$.dioica on Regucalcin level}

\section{RESULTS AND DISCUSSION}

The results of the Table-1, Figure-1 and 2, showed a significant increase $(\mathrm{P} \leq 0.05)$ in the level of regucalcin in group induced by $\mathrm{CCL}_{4}(1,511.27 \pm 103.38)$, as compared with control group (458.83 \pm 7.36$)$. Also, this table revealed the protective effects of both doses of the phenolic extract before and after induced by $\mathrm{CCl}_{4}$. The Results also showed a significant decrease $(\mathrm{P} \leq 0.05)$ in the level of regucalcin as compared with $\mathrm{CCl}_{4}$ induced group.

Table-1: Effect of two concentration of phenolic extract of U.Dioica leaves on the rgucalcin level in hepatotoxicity male rats induced by $\mathrm{CCl}_{4}$.

\begin{tabular}{c|c}
\hline \multirow{2}{*}{$\begin{array}{c}\text { Parameters } \\
\text { Treated }\end{array}$} & Mean \pm SE \\
\cline { 2 - 2 } CCL $_{4}$ & RNG $(\mathrm{pg} / \mathrm{mL})$ \\
\hline 250ph.b & $696.79 \pm 28.37 * *$ \\
\hline 250ph.a & $594.20 \pm 52.27 * *$ \\
\hline 500 ph.b & $597.86 \pm 36.51 * *$ \\
\hline 500ph.a & $577.41 \pm 29.36 * * *$ \\
\hline Control & $458.83 \pm 7.36 \mathrm{~b}$ \\
\hline L.S.D $\leq 0.05$ & 135.17 \\
\hline
\end{tabular}

(Ph: Phenolic extract, a: After, b: Before. Similar letters indicate significant absent, while the different letters indicate a significant presence compared induced groups vs control group. * $\mathrm{P} \leq 0.05, * * \mathrm{P} \leq 0.01, \mathrm{P} \leq 0.001$ compared treated groups vs induced group.)

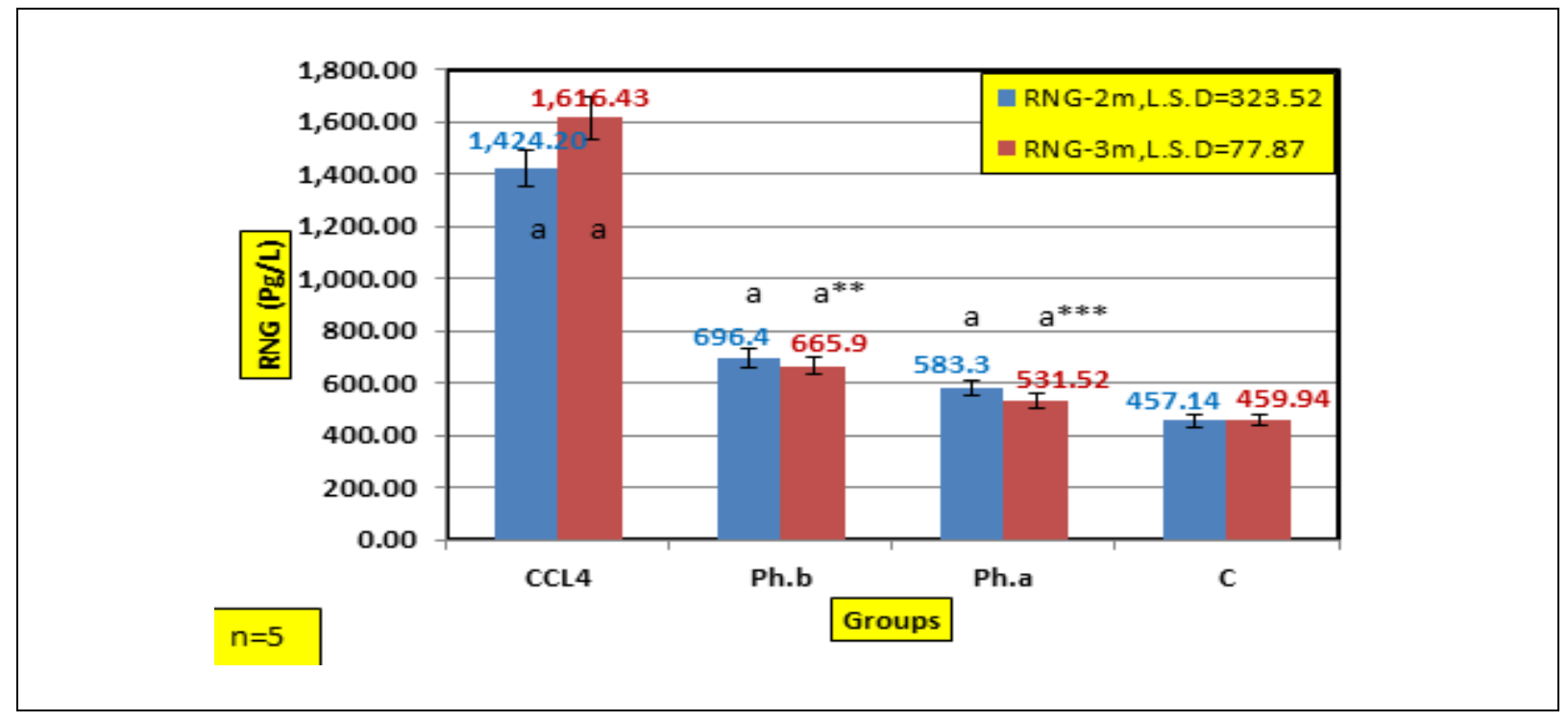

Fig.-1: Effect of duration (two and three month) of a phenolic extract of U.Dioica leaves on RNG level in hepatotoxicity male rats induced by $\mathrm{CCl}_{4}$.

(Ph: Phenolic extract, a: After, b: Before. Similar letters indicate significant absent, while the different letters indicate a significant presence when compared between both periods. ${ }^{*} \mathrm{P} \leq 0.05, * * \mathrm{P} \leq 0.01, * * * \mathrm{P} \leq 0.001$ compared treated groups vs induced group.) 


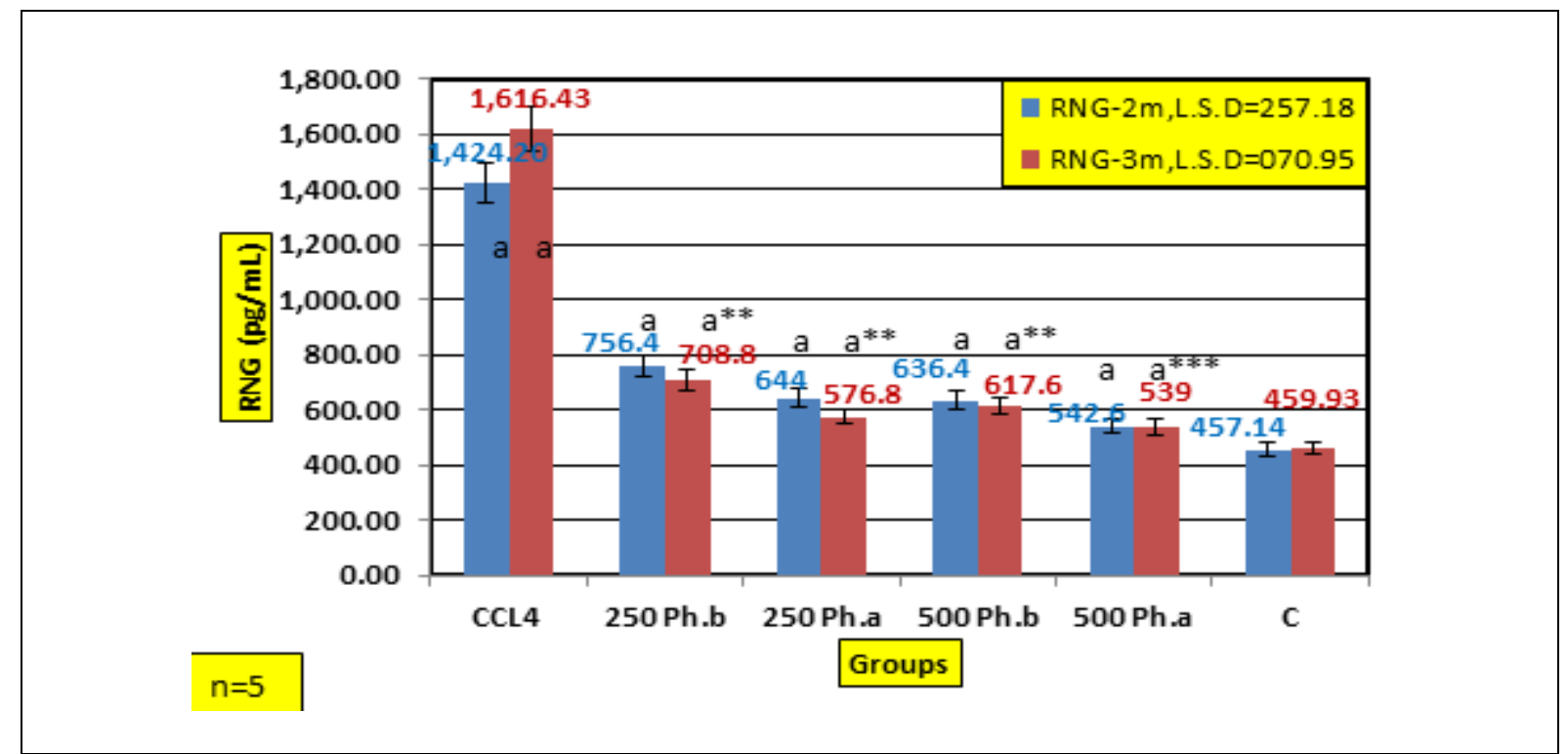

Fig.-2: Effect of interaction between two concentrations (250 and 500mg/kg) and duration (two and three month) of a phenolic extract of U.Dioica leaves on $\mathrm{RNG}$ level in hepatotoxicity male rat induced by $\mathrm{CCl}_{4}$.

(Ph: Phenolic extract, a: After, b: Before. Similar letters indicate significant absent, while the different letters indicate a significant presence when compared between both periods. $* \mathrm{P} \leq 0.05, * * \mathrm{P} \leq 0.01, \mathrm{P} \leq 0.001$ compared treated groups vs induced group.)

\section{Result of silver nanoparticles on Regucalcin level}

The results of the Table-2, Figure-3 and 4, showed a significant increase $(\mathrm{P} \leq 0.05)$ in levels of regucalcin in the induced group by $\mathrm{CCL}_{4}(1,462.81 \pm 140.59)$ as compared with control group $(450 \pm 8.1)$. Also, this table revealed the protective effects of both doses of silver nanoparticles, which showed a significant decrease $(\mathrm{P} \leq 0.05)$ in regucalcin levels of treated groups. It was more obviously that a significant result obtained with a dose $(10 \mathrm{mg} / \mathrm{kg})$ after induction $\mathrm{CCl}_{4}$, as compared with other groups.

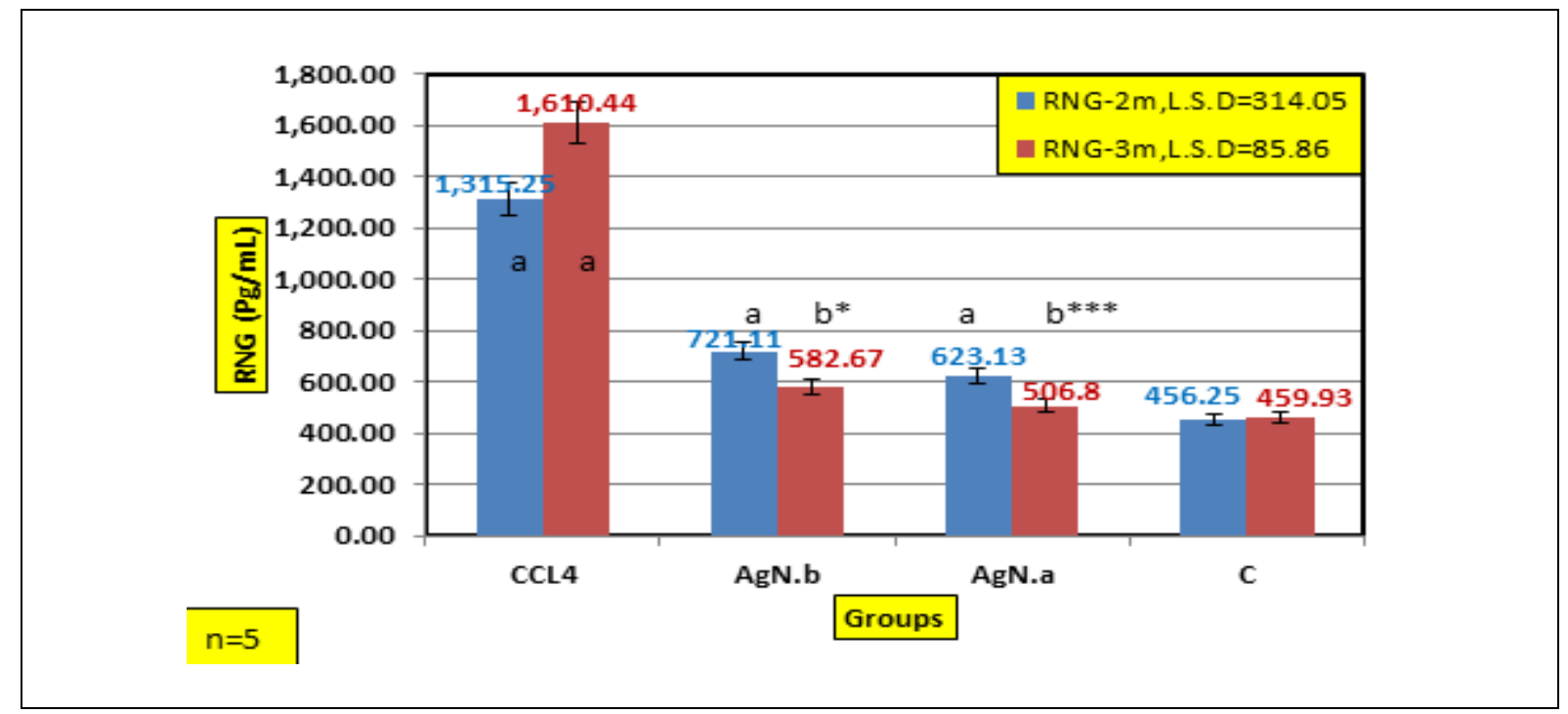

Fig.-3: Effect of periods (two and three months) of silver nanoparticles on the regucalcin level in hepatotoxicity male rats induced by $\mathrm{CCl}_{4}$.

(AgN: Silver Nanoparticles, a: After, b: Before. Similar letters indicate significant absent, while the different letters indicate a significant presence when compared between both periods. ${ }^{*} \mathrm{P} \leq 0.05,{ }^{*} \mathrm{P} \leq 0.01, \mathrm{P} \leq 0.001$ compared treated groups vs induced group.) 
Table-2: Effect of two concentration of silver nanoparticles on the regucalcin level in hepatotoxicity male rats induced by $\mathrm{CCl}_{4}$.

\begin{tabular}{c|c}
\hline Parameters & Mean $\pm \mathrm{SE}$ \\
\cline { 2 - 2 } Treated & $\mathrm{RNG}(\mathrm{pg} / \mathrm{mL})$ \\
\hline $\mathrm{CCl}_{4}$ & $1,462.81 \pm 140.59 \mathrm{a}$ \\
\hline 5AgN.b & $728.50 \pm 52.50 * *$ \\
\hline 5AgN.a & $618.11 \pm 40.05^{* *}$ \\
\hline 10AgN.b & $691.56 \pm 47.19^{* *}$ \\
\hline 10AgN.a & $549.24 \pm 44.08^{* * *}$ \\
\hline Control & $450.00 \pm 8.10 \mathrm{~b}$ \\
\hline L.S.D $\leq 0.05$ & 138.55 \\
\hline
\end{tabular}

(AgN: Silver Nanoparticles, a: After, b: Before. Similar letters indicate significant absent, while the different letters indicate a significant presence compared induced groups vs control group. $* \mathrm{P} \leq 0.05, * * \mathrm{P} \leq 0.01, \mathrm{P} \leq 0.001$ compared treated groups vs induced group.)

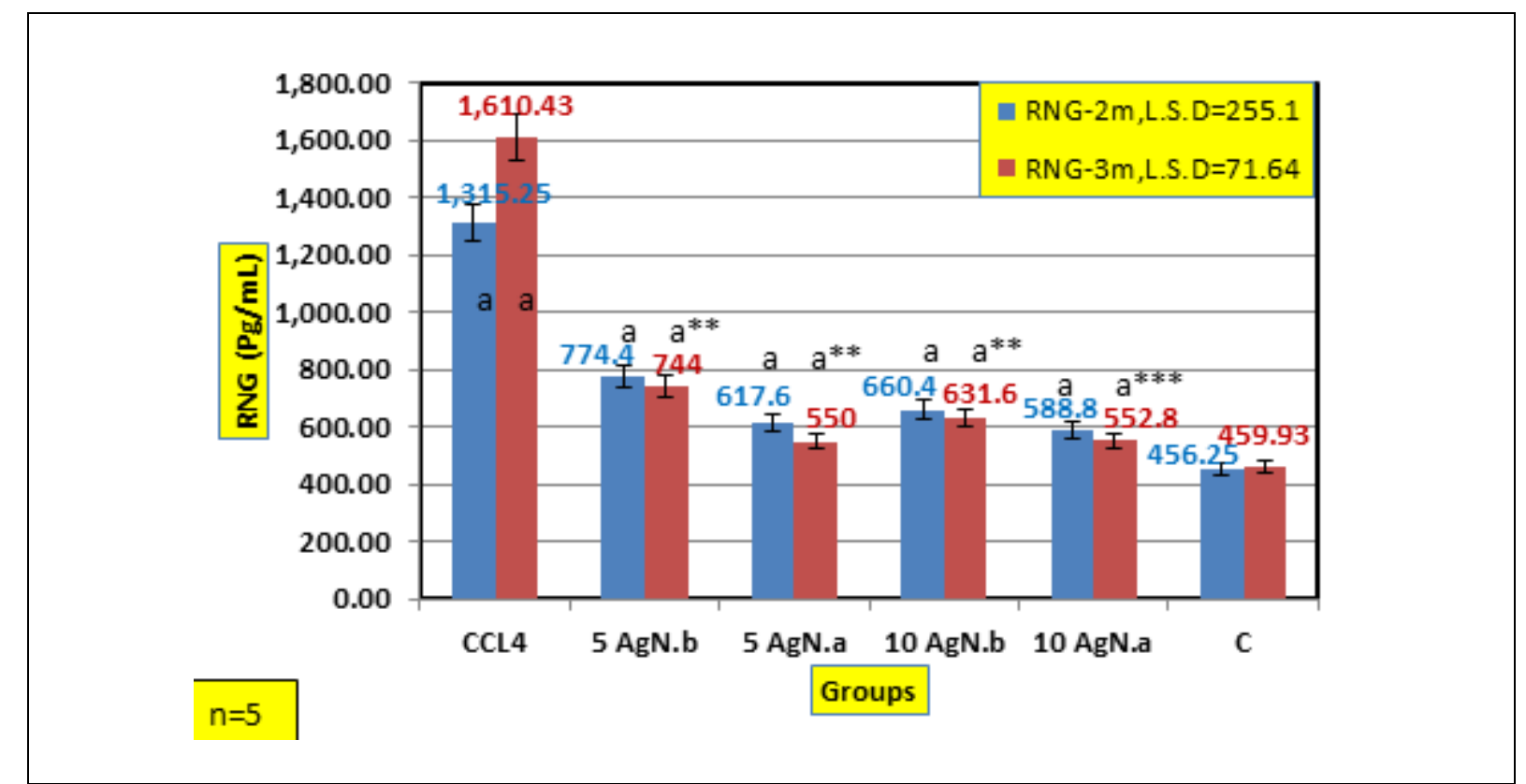

Fig.-4: Effect of interaction between two concentrations and duration (two and three months) to the dosage of silver nano-particles on the regucalcin level in hepatotoxicity male rat induced by $\mathrm{CCl}_{4}$.

(AgN: Silver Nanoparticles, a: After, b: Before. Similar letters indicate significant absent, while the different letters indicate a significant presence when compared between both periods. ${ }^{*} \mathrm{P} \leq 0.05,{ }^{*} \mathrm{P} \leq 0.01, \mathrm{P} \leq 0.001$ compared treated groups vs induced group.)

\section{Study of comparison between phenolic extract of U.Diocia and silver nanoparticles}

The overall result in figure- 5 is indicated no significant differences $(\mathrm{P} \leq 0.05)$ between the effects of an extract of U.Dioica and silver nano-particles on the level of regucalcin.

\section{Study of the effect of $\mathrm{CCl}_{4}$ on Regucalcin level}

The results of a Table-1, Figure-1 and Figure-2 showed a significant increase in regucalcin level after orally administered with $\mathrm{CCl}_{4}$. These results are in agreement with the findings, ${ }^{38-40}$ reported that hepatic regucalcin mRNA expression has been shown to be suppressed by oral administration with $\mathrm{CCl}_{4}$ which is known as a substance-inducer for liver damages. Moreover, they also mentioned that a remarkable increased in the regucalcin concentration in the serum of male rat. The serum regucalcin has a potential sensitivity and specific biochemical marker of chronic liver injury in rats administrated $\mathrm{CCl}_{4}$, and detection 
of a high level of regucalcin was potential for liver damage in the rat. ${ }^{39}$ Marques et al. ${ }^{30}$ mentioned that oral administration of $\mathrm{CCl}_{4}$ down regulator the regucalcin mRNA in a hepatic cell. $\mathrm{CCl}_{4}$ administration has also been shown to increase $\mathrm{Ca}^{+2}$ contained in the rat liver suggestion that disturbance of intracellular $\mathrm{Ca}^{+2}$ homoeostasis by regulating $\mathrm{Ca}^{+2}$ binding protein activity such as $\mathrm{Ca}^{+2}$-ATPase calmodulin kinase and PKC. ${ }^{41}$

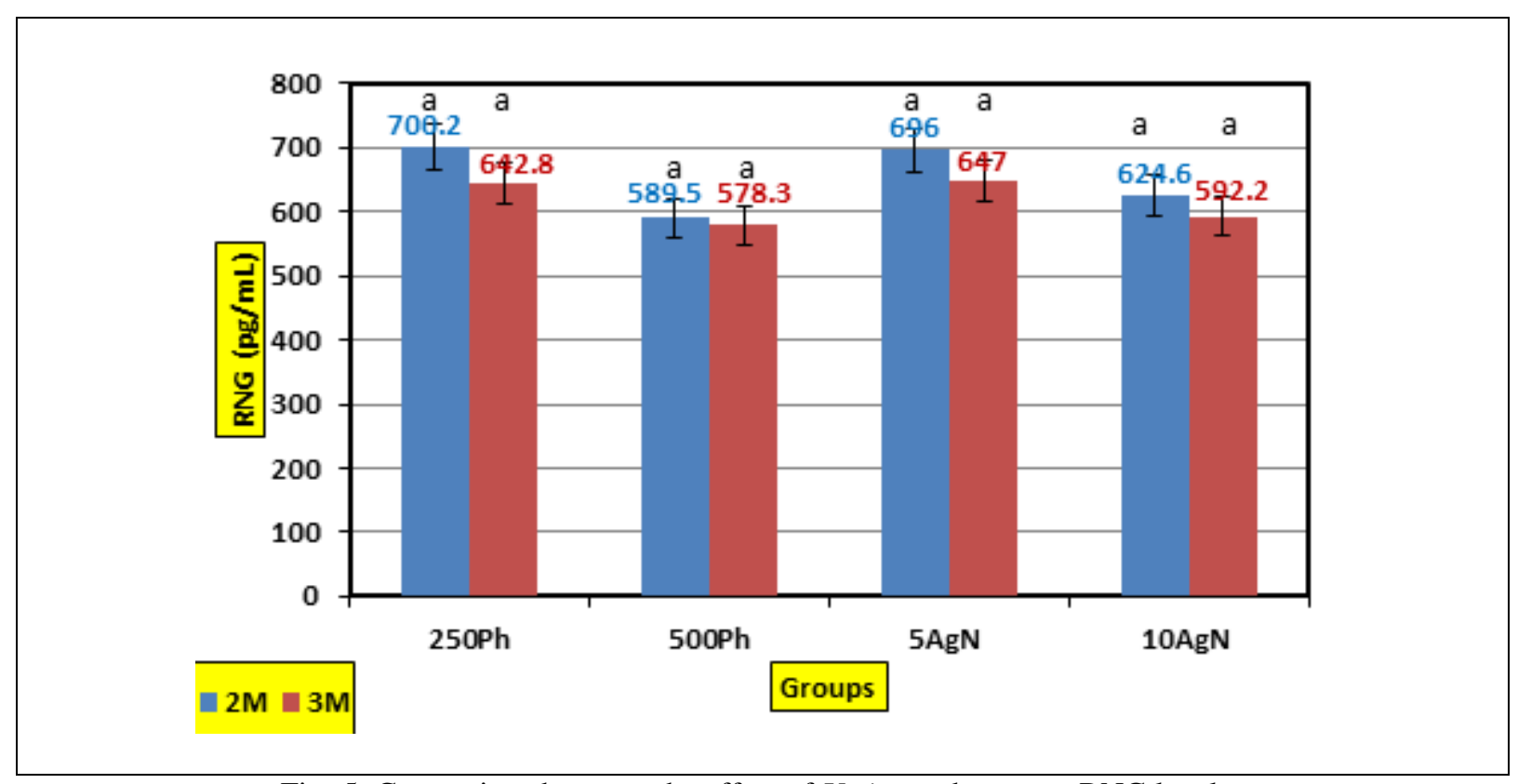

Fig.-5: Comparison between the effect of Urtica and nano on RNG level.

(AgN: Silver Nanoparticles, Ph: Phenolic extract, a: After, b: Before. Similar letters indicate significant absent, while the different letters indicate a significant presence when compared between both periods.)

\section{Study of the effect of $\boldsymbol{U}$.dioica on Regucalcin level}

The results of a Table-1, Figure-1 and Figure-2 indicates a significant decrease in regucalcin level after orally administered with U.dioica. These findings are in agreement with the findings of Gilani and Janbaz ${ }^{42}$ who stated that $U$. dioica is hepatoprotective that may lead to decrease regucalcin level as a result of regeneration in mice liver cells after their damage by $\mathrm{CCl}_{4}$. The Phytochemical analysis of U.dioica showed it contain (alkaloid, flavonoid, terpenoid, tannin, phenolic and several of minerals elements) which has hepatoprotective activity through its free radical scavenger. ${ }^{14,43,44}$ The previous study has suggested that regucalcin can directly bind and stimulate $\mathrm{Ca}^{+2}$ pump activity. ${ }^{45,46}$ Therefore, the phenolic compound of U.dioica may play an important role in decreasing $\mathrm{Ca}^{+2}$ pumping activity and maintain both cell homoeostasis and function that led to decrease regucalcin level ${ }^{47-49}$. The present study suggest that, the phenolic compound of $U$. dioica has a protective role against $\mathrm{CCL}_{4}$ that may lead to decrease regucalcin level in serum via decreasing attracting of $\mathrm{CCl}_{4}$ with liver membrane and to increase membrane fluidity, as well as, damage to membrane protein and to increase of membrane antioxidant defence enzyme because of this richness of U.dioica with phenolic compound that may provide a good source of antioxidant these findings are in accordance the other findings. ${ }^{50,51}$

\section{Study of the effect of AgNPs on Regucalcin level:}

Table-2, Figure-3 and Figure-4 showed a significant decrease in regucalcin level after oral administration of silver nanoparticles. Kataki et al. and Sung et al. mentioned that liver was the main target organ for AgNPs and the hepatoprotective effect of nanoparticles depend on the size of particles, therefore, the toxicity of smaller particles produce the more cytotoxic response. ${ }^{52,53}$ Using large nanoparticles (50nm) after characteristics by scanning electron microscope, are considered more safety for human and rat 
health ${ }^{54-56}$. The decrease in regucalcin level in the present study was the result of liver regeneration by evoking an increase intracellular $\mathrm{Ca}^{+2}$ amount which is in agreement with other findings, ${ }^{57,58}$ who reported that AgNPs are able to interfere with liver cellular function and specific biological system. The ability of nanomaterial for translocated in circulation may be modified regucalcin protein by interfering with its function. $^{44,59,60,61}$

\section{CONCLUSION}

Administration of experimental male rats with carbon tetrachloride for two and three months represented a causative factor in inducing the hepatotoxicity and initiation of cirrhosis.

Both of them Urtica dioica and silver nanoparticles have a protecting role against carbon tetrachloride by its effect on free radical scavenger and activation of the antioxidant system especially at high dose and duration of time.Urtica dioica and silver nanoparticles are capable protecting the liver from the effect of carbon tetrachloride.

\section{ACKNOWLEDGEMENT}

The authors would like to express their deep gratitude towards The science College and the Department of biology, Kufa University, for their continuous support and encouragement during this work.

\section{REFERENCES}

1. L. T. Hoekstra, et al., Ann. Surg., 257, 27(2013).

2. S. G. Sakka, Curr. Opin. Crit. Care, 13, 207(2007).

3. H. Rivera, M. Shibayama, V. Tsutsumi, V. Perez-Alvarez, and P. Muriel, J. Appl. Toxicol., 28, 147 (2008).

4. M. R. Khan, W.Rizvi, G. N. Khan, R. A. Khan, and S. Shaheen, J. Ethnopharmacol, 122, 91 (2009).

5. H.-Y. Kim, et al., J. Pharmacol. Sci., 112, 105(2010).

6. N. Tirkey, S. Pilkhwal, A. Kuhad, and K.Chopra, BMC Pharmacol., 5, 1(2005).

7. Y. Ohta, et al., J. Clin. Biochem. Nutr., 42, 118(2008).

8. H. Kandis, S. Karapolat, U. Yildirim, and A. Saritas, Clinics, 65, 1357(2010).

9. O. Krystofova, et al., Int. J. Environ Res. Public Health, 7, 3804(2010).

10. M. J. Golalipour, S. Ghafari, and M. Afshar, Turkish J. Gastroenterol., 21, 262(2010).

11. J. Vandenbroucke, R. Bogaert, and R. De Graeve, Belg. Tijdschr. Geneesk., 7, 97(1951).

12. H. Bliddal, and R. Christensen, Expert Opin. Pharmacother., 10, 1793(2009).

13. S. Gül, B. Demirci, K. H. C. Başer, H. A. Akpulat, and P. Aksu, Bull. Environ. Contam. Toxicol., 88, 666(2012).

14. M. S. Khalifeh, W. Hananeh, R. Al-Rukibat, O. Okour, and A. Boumezrag, Exp Anim, 57, 101 (2008).

15. I. Hadizadeh, B. Peivastegan, and M. Kolahi, Pakistan J. Biol. Sci., 12, 58(2009).

16. H. J. Hammod, A. N. Al-Dujaili, and M. N. Al-Dujaili, Res. J. Pharm. Biol. Chem. Sci., 7, 809 (2016).

17. H. J. Hammod, A. N. Al-Dujaili, and M. N. Al-Dujaili, Res. J. Pharm. Biol. Chem. Sci., 7, 804 (2016).

18. A. Noori Al-Dujaili, , A. Baqir Hassan, and N. Saleh Mahdi, Rasayan J. Chem., 9(4), 566 (2016).

19. Y. Ju-Nam, and J. R. Lead, Sci. Total Environ., 400, 396(2008).

20. P. Pardhasaradhi, G. Giridhar, K. Pandian, and V.G. K. M. Pisipati, Rasayan J. Chem., 10(1), 69 (2017).

21. C. Antoniades, et al., Circulation, 122(11), S66 (2010).

22. C. Antoniades, et al., Curr. Drug Deliv., 7, 303(2010).

23. S. Hussain, and C. Ferguson, Emerg. Med. J., 23, 929(2006).

24. A. Nel, T. Xia, L. Mädler, and N. Li, Science, 311, 622(2006).

25. P. Møller, et al., Crit. Rev. Toxicol., 41, 339(2011).

26. M. Yamaguchi, Mol. Cell. Biochem., 346, 147(2011).

27. P. Lai, N. C. Yip, and F.Michelangeli, FEBS Lett., 585, 2291(2011).

28. K. Y. Arai, et al., Biochem. Biophys. Res. Commun., 385, 478(2009).

29. Y. Kondo, et al., Biochem. Biophys. Res. Commun., 377, 291(2008).

30. R. Marques, C. J. Maia, C. Vaz, S. Correia, and S. Socorro, Cellular and Molecular Life Sciences, 71, 93(2014). 
RASĀYAN J. Chem.

Vol. 10 | No. 2 |305 -312 | April - June | 2017

31. R. Marques, et al., Exp. Cell Res., 330, 325(2015).

32. M. Yamaguchi, Cell Prolif., 46, 243(2013).

33. M. Yamaguchi, J. Molecular and Cellular Biochemistry, 341, 119(2010).

34. M. N. Al-Seeni, H. A. El Rabey, M. A. Zamzami, and A. M. Alnefayee, BMC Complement. Altern. Med., 16, 438 (2016).

35. J. D. C. Ctab, Young, 57, 13(1991).

36. C. Proestos, D. Sereli, and M. Komaitis, Food Chem., 95, 44(2006).

37. A. C. Elliott, and W. Woodward, Statistical Analysis Quick Reference Guidebook: With SPSS Example, Sage Publication, p.280 (2007).

38. M. Yamaguchi, Y. Morooka, H. Misawa, Y. Tsurusaki, and R. Nakajima, J. Cell. Biochem., 86, 520(2002).

39. M. Yamaguchi, M. Isogai, and N. Shimada, Mol. Cell. Biochem., 167, 187(1997).

40. M. Isogai, K. Oishi, and M. Yamaguchi, Mol. Cell. Biochem., 136, 85(1994).

41. Noor Mohammed, et al., Journal of Clinical \& Experimental Pharmacology, 6(2), 1(2016).

42. A. U. H. Gilani, and K. H. Janbaz, Gen. Pharmacol., 26, 309(1995).

43. H. Saleem, A. N. G. Al-Dujaily, and M. H. H. Al-Murshidi, Res. J. Pharm. Biol. Chem. Sci., 7, 2222 (2016).

44. H. Saleem, A. N. G. Al-Dujaily, and M. H. H. Al-Murshidi, Res. J. Pharm. Biol. Chem. Sci.,7, 2210 (2016).

45. M. Yamaguchi, Y. Tsurusaki, H. Misawa, and S. Inagaki, Mol. Cell. Biochem., 241, 61(2002).

46. M. Yamaguchi, Y. Takakura, and T. Nakagawa, J. Cell. Biochem., 104, 795(2008).

47. A. Krasnov, M. Reinisalo, T. I. Pitkanen, M. Nishikimi, and H. Molsa, Biochim. Biophys. Acta, 1381, 241(1998).

48. K.K. Juma, S.G. Maina, J.N. Muriithi, B.M. Mwangi, K.J. Mworia, M.J. Mwonjoria, J.N. Ngeranwa and N.D. Mburu , J. Dev. Drugs 4(2), 130 (2015).

49. N. Shimokawa, and M. Yamaguchi, FEBS Lett., 327, 251(1993).

50. B. C. Joshi, A. Prakash, and A. N. Kalia, Toxicol. Reports, 2, 1101(2015).

51. M. S. Kataki, et al., Pharm. Crop., 3, 38(2012).

52. Y. S. Kim, et al., Part. Fibre Toxicol., 7, 20 (2010).

53. J. H. Sung, et al., Toxicol. Sci., 108, 452(2009).

54. F. M. Matschinsky, et al., Diabetes, 55, 1(2006).

55. G. Oberdörster, Journal of Internal Medicine, 267, 89(2010).

56. G. M. Srirangam, and K. P. Rao, Rasayan J. Chem., 10(1), 46(2017).

57. A. Haase, et al., Restor. Neurol. Neurosci., 28, 672(2010).

58. H.-J. Zhai, D.-W. Sun, and H.-S. Wang, J. Nanosci. Nanotechnol., 6, 1968(2006).

59. A. N. G. Al-Dujaili, and M. K. Al-Shemeri, Res. J. Pharm. Biol. Chem. Sci., 7, 1022(2016).

60. A. Noori Ghani Al-Dujaili, and M. Kadhim Al-shemeri, Res. J. Pharm. Biol. Chem. Sci., 7, 975 (2016)

61. K. Sivaram, et al., Rasayan J. Chem., 10(1), 16 (2017).

[RJC-1631/2017] 